entirely hypothetical series of upward and downward movements. These are unnecessary if we can be convinced that coral-reefs grow up independent of terrestrial movements, which may in one area be in an upward, in another in a downward direction. From this point of view the reefs stand up as the result of a complex series of agencies, among which the more important are on the one hand, the temperature, solvent power, currents, tides, and waves of the sea, and on the other hand, the amount and direction of the supply of pelagic food, the up. building of calcareous deposits to the zone of reef-builders, the outward vigorous growth of the coral-masses and their decay and death, and the solution of their skeletons in the inner parts of the reefs. All these causes are known and visibly active. Without the cooperation of any other supposed or latent force they appear to be entirely adequate to the task of building up the present coral-reefs of the oceans. ARCH. GEIKIE

\section{DR. JOHN LAWRENCE LECONTE}

I NFORMATION has just been received in this country announcing the death of Dr. LeConte. He was born in New York on May 13, 1825, and was the son of a distinguished officer in the United States army, himself an entomologist. He aciopted the medical profession, and during the secessionist war he entered as medical officer of volunteers. The foregoing necessarily brief, specially biographic account is chiefly derived from information furnished in Dimmock's "Special Bibliography of American Entomologists, No. I."

LeConte could have been only nineteen years old when he published his first entomological paper on certain new species of North American Coleoptera (Proceedings of the Academy of Natural Sciences of Philadelphia, vol. ii.) From that time forward a continuous series of works and papers on North American Coleoptera was produced by him until his death. He made a speciality of Coleoptera, and, with few exceptions, all his writings were devoted to that order of insects, and through his exertions the beetles of the United States are now almost as well known as are those of Europe. At the time of his death his published papers must have been nearly 200. Moreover he was the acknowledged authority in the United States on all matters coleopterological, a position which must naturally have caused him vast trouble and correspondence, sometimes with inadequate results. Latterly he worized greatly in company with Dr. G. H. Horn, of Philadelphia, a worthy follower of his tutor and a worthy successor. Their joint labours culminated this year, when was published ("Smithsonian Miscellaneous Collections," No. 507) a "Classification of the Coleoptera of North America," a volume extending to nearly 600 pages. It is needless here to refer to the revolution this work and other memoirs (chiefly by Dr. Horn) created in the minds of coleopterists as to the sequence of main divisions, \&c. All working entomologists are sufficiently alive to the importance of the new ideas put forth. In fact this volume might have been considered a model of a special monograph were it not for a somewhat crude "Introduction" on insects in general that precedes the systematic portion.

In the present condition of entomological science in the United States the loss of Dr. LeConte seems almost irreparable. He and his coadjutor, Dr. Horn, and one or two others, stood almost alone amongst the prominent American entomologists in holding no special official position in connection with their subject.

LeConte once made a lengthy stay in Europe, and was well known personally in this country to all the prominent Coleopterists. Moreover he was honorary member of several of the European entomological societies, including the Entomological Society of London; his personal friends in this country were numerous. Since the death of
Say (whose scattered works were carefully collated and reedited by the subject of this notice) entomological science in America has not had to deplore so severe a loss, and Say's death was not fraught with the same significance.

R. MCLACHLAI

THE LATE MR. DARWIN ON INSTINCT

$A^{\mathrm{T}}$ the meeting of the Linnean Society this evening (December 6) a highly interesting posthumous paper on Instinct, by Charles Darwin, will be read and discussed. We have been favoured with an early abstract of the same, which we here present to our readers.

After detailing sundry facts with reference to the migratory instincts of different animals, Mr. Darwin proceeds to suggest a theory to account for them. I his theory is precisely the same as that which was subsequently and independently enunciated by Mr. Wallace in NATURE, vol. x. p. 459. Thus, to quote from the essay: "During the long course of ages, let valleys become converted into estuaries, and then in to wider and wider arms of the sea; and still. I can well believe that the impulse [originally due to seeking food] which leads the pinioned goose to scramble northward, would lead our bird over the trackless waters; and that, by the aid of the unknown power by which many animals (and savage men) can retain a true course, it would safely cross the sea now covering the submerged path of its ancient journey."

The next topic considered is that of instinctive fear. Many facts are given, showing the gradual acquisition of such instinctive fear, or hereditary dread, of man, during the period of human observation. These facts led Mr. Darwin to consider the instinct of feigning death as shown by sundry species of animals when in the presence of danger. Seeing that "death is an unknown state to each living creature," this seemed to him "a remarkable instinct," and accordingly he tried a number of experiments upon the subject with insects, which proved that in no one case did the attitude in which the animal "feigned death" resemble that in which the animal really died; so that the instinct really amounts to nothing else, in the case of insects at all events, than an instinct to remain motionless, and therefore inconspicuous, in the presence of danger. From the facts given with regard to certain vertebrated animals, however, it is doubtful how far this explanation can be applied to them.

A large part of the essay is devoted to "Nidification and Habitation," with the object of showing, by an accumulation of facts, that the complex instincts of nestbuilding in birds and of constructing various kinds of habitations by mammals, all probably arose by gradual stages under the directing influence of natural selection.

The essay concludes with a number of "miscellaneous remarks" on instincts in general. First the variability of instinct is proved by sundry examples; next the fact of double instincts occurring in the same species; after which, "as there is often much difficulty in imagining how an instinct could first have arisen," it is thought "worth while to give a few, out of many cases, of occasional and curious habits, which cannot be considered as regular instincts, but which might, according to our views, give rise to such." Finally, cases of special difficulty are dealt with; these may be classified under the following heads:-(r) Similar instincts in unallied animals; (2) dissimilar instincts in allied animals; (3) instincts apparently detrimental to the species which exhibit them; (4) instincts performed only once during the lifetime of an animal ; (5) instincts of a triffing or useless character; (6) special difficulties connected with the instinct of migration; (7) sundry other instincts presenting more or less difficulty to the theory of natural selection.

The "Conclusion" gives a summary of the general 